\title{
Social networking and privacy attitudes among college students
}

\author{
Kristen A. Carruth* and Harvey J. Ginsburg \\ Texas State University, USA
}

(Received March 3, 2014; Accepted July 29, 2014)

\begin{abstract}
Daily use of social networking sites (SNS) such as Facebook has become routine for millions of Internet users. Facebook is currently still the most popular social media site. Social networking has been rapidly adopted by societies around the world. In particular, social media like Facebook provide sites where users can personalize a profile with their information, pictures, and videos that can be shared with other users. This information can be used in ways that may violate users' privacy with or without their knowledge. The hypotheses were that use of Facebook, user self-efficacy for social media and users' general attitudes about privacy expectations are predictors of specific attitudes towards Facebook social media privacy, among a sample of 284, mostly white female, undergraduate college students in their twenties. Facebook self-efficacy and Facebook personal privacy violations were significant determinants of general Internet social media privacy concerns. However, Facebook use was not a significant factor for general Internet social media privacy concerns. Perceived benefits of Facebook generally appear to outweigh risks of disclosing personal information.
\end{abstract}

Keywords: social media, self-efficacy, Facebook.

Las redes sociales y las actitudes de privacidad entre los estudiantes universitarios

RESUMEN: El uso diario de las redes sociales (SNS), tales como Facebook, se ha convertido en rutina para millones de usuarios de Internet. Facebook es actualmente todavía la red social más popular. Las redes sociales han sido rápidamente adoptadas por las sociedades de todo el mundo. En particular, las redes sociales como Facebook ofrecen sitios donde los usuarios pueden personalizar un perfil con sus datos, fotografías y vídeos que se pueden compartir con otros usuarios. Esta información se puede utilizar en maneras que pueden violar la privacidad de los usuarios, con o sin su conocimiento. Las hipótesis fueron que el uso de Facebook, la auto-eficacia del Usuario para los medios sociales y las actitudes generales de los usuarios acerca de las expectativas de privacidad se mostarían como predictores de las actitudes específicas hacia la privacidad de los medios de comunicación de Facebook en una muestra de 284 estudiantes universitarios de grado, en su mayoría mujeres blancas de unos veinte años. La autoeficacia en Facebook y las violaciones de privacidad personal en Facebook, fueron determinantes significativos de las preocupaciones sobrela privacidad general de los medios sociales en Internet. Sin embargo, el uso de Facebook no fue 
un factor significativo para la preocupación sobre la privacidad general de las redes sociales en internet. Los beneficios percibidos de Facebook en general parecen superar los riesgos percibidos sobre la revelación de información personal. Palabras clave: redes sociales, autoeficacia, Facebook.

Since the introduction of the Internet, people from around the world have been drawn to their computer screens. The Internet provides an easy way to communicate and reach millions of people instantly. Many Internet users spend their time on social networking sites (SNS), which provide them with a wide array of services. Many SNS support already existing social networks, but they can also offer a place for people to reach out to other users who share similar interests. Some sites also provide ways to share information as well as send messages, play games, and share photos/videos. The daily use of SNS such as Facebook has become a routine for millions of Internet users. According to the Pew Research Center, the number of people in the U.S. using social networking sites has nearly doubled since $2008,59 \%$ of Internet users compared to $34 \%$. As a result, SNS are not just an Internet phenomenon, but also a useful technological innovation that is being adopted on a massive scale by societies around the world (Gross \& Acquisti, 2005). Facebook is currently the most widely used social media site among adult Internet users (Duggan \& Smith, 2014).

Boyd and Ellison (2008) defined social networking sites as web-based services allowing people to (1) create public personal profiles within a bounded system, (2) share information with other users with whom they are connected, and (3) view and traverse connections among others within the system. What makes social networking sites so appealing is their ability to connect individuals who otherwise would not have been able to communicate. Many of these users aren't networking to meet new people; most users want to connect with their already existing social networks.

User profiles can be filled with information provided by the individual, as well as pictures, videos, and status updates, providing a small window into the user's life. The information provided by users can be seen by their social network, which may include family, friends, and co-workers, all of whom also subscribe to the SNS.

After joining a SNS, simple questions can be answered, like age, marital status, and interests, to begin the personalization of their profile. The user fills in an "About Me" section, providing a profile photo, if he or she so chooses. Some sites also allow users to change the look and feel of their profile, while others, like Facebook, provide a template to add information and applications to enhance the profile. The visibility of a profile changes from site to site, and many are up to the user's discretion. Some profiles, like on the website Friendster, may be visible to anyone on the Internet. Users on the site Myspace have the option to make their profile public or private, and Facebook, by default, allows users to view other profiles in the same network, unless the profile owner changes their settings to private. After joining the site and filling in some information, users are prompted 
to seek out others with whom they share a personal relationship.

The label given to certain relationships varies across different sites; Facebook uses the label "Friends" which can include not only friends, but other personal relationships as well. Public display of "Friends" is a crucial component of SNS (Boyd \& Ellison, 2008). The list contains links to each users' profile, enabling viewers to search for relationships through others' networks. Most SNS provide messaging services that allow users to send either a private message or post a comment on another user's profile. Facebook also allows users to chat with others who they are friends with and happen to be on the website at the same time. Beyond these messaging services, SNS also provide a way for users to share photos, videos, and links to separate websites. Many SNS, including Facebook, connect users living in the same geographical area or users who share specific information, like high school and certain friends. The features provided by SNS provide an explanation as to why they are so successful and why individuals have integrated them into their daily lives.

According to Boyd and Ellison, the first SNS was developed in 1997, Sixdegrees.com. By allowing its users to create profiles, friends' lists, and have the lists publicly displayed, Sixdegrees.com shared several common attributes found in modern social networking sites. By the end of 2006, Facebook had emerged as the most popular SNS, connecting over 12 million active users. Today, Facebook reports an estimated figure of more than a billion active users on the website; $75 \%$ of Facebook users live outside of the United States.

Social networking sites have become ubiquitous in our culture, mostly due to their rapid use on the Internet. Young people are usually at the forefront of popular social media and this has been shown to be true in SNS use. Barker (2009) investigated the motives for SNS use of older adolescents, focusing on social identity issues as well as gender. She found that positive collective self-esteem, the aspect of identity that has to do with the value placed upon group membership, strongly correlated with communication in peer groups using SNS and negative collective self-esteem was moderately related to social compensation (those who feel negative about their social group may use a SNS to communicate with other group members). As for gender differences, communicating with peer groups was highly correlated for girls and there was a small but significant difference for males who used SNS for learning. In summary, females were more likely to use SNS to communicate with peers, pass time, and entertain themselves while males were more likely to use SNS to seek social compensation, SIG (social identity gratification), and learning. Most of the participants who reported high collective self-esteem also reported high SNS use to communicate with peer group members, and females reported more interest in this type of communication, especially for entertainment and passing time. Those who reported negative collective self-esteem reported more interest in SNS use for social compensation, learning, and SIG. Males were more likely to report these interests. These findings suggest that those who were insecure about face-to-face interactions were more likely to use the Internet for interactions with others. 
Hargittai (2007) composed a study that examined the differences between users and non-users of social networking sites. Facebook is the most popular service among the students surveyed, with almost four out of five using it, and over half of the overall sample doing so frequently. Myspace is used by more than half of the sample, although just over one-third uses it often. The other four sites (Xanga, Friendster, Orkut, and Bebo, in that order of popularity) are significantly less widespread in this group.

The differences among the user populations of these sites are small, but some of the trends are notable. First, the percentage of Asian/Asian American users varies, depending on the service. In particular, Asian/Asian American students in the sample are least represented on Myspace, whereas Xanga and Friendster are especially popular with this group. Second, students of Hispanic origin make up a considerably larger segment of Myspace users than their representation in the sample.

Since it has long been known that people tend to socialize and spend time with others like them (Marsden, 1987), it is reasonable to expect that students from similar backgrounds might migrate toward the same services. Third, there is a relationship between parental education and use of some SNS. In particular, students who have at least one parent with a graduate degree are more represented on Facebook, Xanga, and Friendster than they are in the whole sample, while students whose parents have less than a high school education are disproportionately users of Myspace. The researchers also found that women are more likely to use SNS than their male counterparts.

However, in addition to gender, both context of use and experience with the sites are related to the adoption of the services. In particular, students who live at home with their parents are less likely to use SNS than those who live with roommates or on their own. A possible reason for these results is that by spending less time on campus, students who live with their parents know fewer of their peers and know less about them, thus perhaps having less of a desire to keep in touch with them by using social network sites. Regarding experience, how long someone has been online is not related to SNS usage, but SNS use results in people spending more time online. Thus, based on what is known about these sites, it is fair to assume that one's existing offline network influences which site a person chooses to use. Forming relationships with members of one's cohort is an important part of the college experience, and one could argue that services like Facebook facilitate such interactions.

Brandtzæg, Lüders, and Skjetn (2010) explored content sharing and sociability, and how they affect privacy experiences and usage behavior among SNS users. When interviewed, parents were found to be motivated to use Facebook as part of their parental monitoring, whereas the younger participants use it to keep informed about when and where to meet their friends and classmates. Although younger users mainly joined Facebook because of their friends, older adults and those who had children on Facebook said that checking up on their children was their main reason for starting to use Facebook. In addition to contact with new 
and old friends, the participants emphasized that they have had more contact with close and distant members of their families since joining Facebook.

Brandtzæg, et al found two factors related to privacy concerns with social networks. First, the interviews revealed that Facebook users in all age groups reported more contact with several different groups of people, which reflect different types of social capital (i.e., family, friends, and acquaintances), because of Facebook, but not without consequences for privacy. Having too many Facebook "friends" and access to different social capital disrupt the sharing process due to experiences of social surveillance and social control. This social control often forces younger people in particular to use conformity as a strategy when sharing content to maintain their privacy. The interviews revealed different motivations and usage patterns when older and younger users are compared. Second, the usability test found a significant difference between younger and older adults in time completion and task completion related to Facebook settings. Younger users were more skilled in their Facebook usage, whereas adults over the age of 40 had difficulties in understanding the navigation logic and privacy settings. Additionally, younger and older adults often displayed completely open public profiles without realizing it. The results from this study show that the presence of increasingly multiple social ties and groups on Facebook affects the experiences of social privacy in terms of social surveillance. This in turn affects young people's user behavior, as they often experience increased self-awareness and choose conformity as a way to maintain their social privacy.

Debatin et al. (2009) investigated Facebook users' awareness of privacy issues and perceived benefits and risks of using Facebook. Specifically, they examined the relationship of Facebook privacy issues, privacy settings, perceived benefits and risks, routinization and ritualization, and invasion of privacy to self and others. They surveyed 119 college students, and selected 8 participants to conduct open-ended face-to-face interviews. For the survey measures, they asked participants about their demographic characteristics, general Facebook habits, user practices with regard to privacy, the role of friends in Facebook use, and the potential risks of Facebook. Participants were asked whether they had encountered any or all of these problems on Facebook: unwanted advances, damaging gossip, or personal data abuse by others. Participants further indicated whether they knew a person who was affected by any of these negative incidents, and, if so, how the participant reacted to hearing about it. This was included in order to examine differences between perceived negative incidents to oneself and those perceived about others. Using survey answers, 8 individuals were also brought in for interviews. The main categories the researchers used to identify and interpret statements were (1) invasion of privacy, (2) breach of trust, (3) violation of boundaries, (4) gossip and rumors, and (5) habitual or ritualized use of Facebook. The interviews were included so that the research would give a deeper insight into behaviors and attitudes relating to Facebook use and privacy issues, narratives about the attraction, relevance, and usage of Facebook, and experiences about invasion of privacy on Facebook. 
To summarize, Debatin et al. survey results showed that Facebook is currently the most widely used social media site among adult Internet users. The majority of Facebook users report having an understanding of their privacy settings and use them, but they may have a skewed sense of what that really entails. Also, the perceived benefits of Facebook outweighed risks of disclosing personal information. The risks to privacy were attributed more to others than to the self and if Facebook users reported an invasion of personal privacy, they were more likely to change privacy settings than when they reported hearing of an invasion of privacy happening to others. The findings from interviews corroborate the survey findings. The benefits of Facebook outweigh privacy concerns, even when the user experienced privacy invasion.

Self-efficacy perceptions about one's computer use, Internet and SNS competencies may be another variable related to individual differences in expectations of personal control of SNS privacy. Bandura (1994) defined self-efficacy as peoples' beliefs about their capabilities to produce designated levels of performance that exercise influence over events that affect their lives. Beliefs about self-efficacy determine how people feel, think, motivate themselves and behave. People with a strong sense of self-efficacy approach difficult tasks and view them as a challenge to master. Failure is attributable to a lack of effort or knowledge of skills. Threatening tasks are met with confidence. In contrast, people with a weak sense of self-efficacy view challenges as threats that should be avoided. If they are faced with difficult tasks, they focus on their deficiencies and potential adverse effects rather than the task, which causes them to falter and give up quickly.

Individual differences in beliefs about self-efficacy can be produced by four sources of influence: mastery experiences, vicarious experiences, social persuasion, and emotional states (Bandura, 1997). The most effective way to gain a sense of self-efficacy is by mastery experience. Success strengthens a person's self-efficacy, while failure undermines it. A true sense of self-efficacy is acquired when one overcomes obstacles with perseverance and resilience, and is able to reach their goal. Vicarious experiences are another way of strengthening one's self-efficacy. Observing people that are similar to you succeed by using hard work and dedication raises one's belief of being capable of mastering similar techniques. Social persuasion can also be an effective way of raising a person's self-efficacy. If they are verbally encouraged and persuaded that they are able to succeed, it is more likely that they will put forth more effort and sustain that effort to succeed. People's emotional states also have an effect on their ability to succeed. They may equate stress or fatigue with signs of failure or vulnerability. People's mood, whether positive or negative, can also have an effect on a person's self-efficacy. All of these factors can play a key role in the development of a person's self-efficacy (Bandura, 2012).

Compeau and Higgins (1995) surveyed managers' and professionals' computer self-efficacy. Several hypotheses related to self-efficacy were tested, including encouragement of others, other's use, support, computer self-efficacy, outcome expectations, affect, and anxiety. They found that computer self-efficacy had a 
significant influence on individuals' expectations of the outcomes of using computers, their emotional reactions to computers (affect and anxiety), as well as their actual computer use. Self-efficacy was found to play an important role in shaping individuals' feelings and behaviors. Individuals in this study with high self-efficacy used computers more, received more enjoyment from their use, and experienced less computer anxiety. An individual's self-efficacy was positively influenced by encouragement, as well as others' use of computers.

Peng, Tsai, and $\mathrm{Wu}$ (2006) investigated college students' attitudes and selfefficacy towards the Internet, as well as the role that college students' perceptions of the Internet play in their attitudes towards the Internet. Using the Internet attitudes survey (IAS) for assessing students' Internet attitudes and the Internet self-efficacy survey (ISS) for measuring students' Internet self-efficacy, they found that students tended to appreciate the potential usefulness of the Internet, to demonstrate positive feelings when using the Internet, to feel confident about the independent control of their use of the Internet and to use the Internet frequently. Also, for gender differences between attitudes and self-efficacy, the male students expressed more confidence in their use of the Internet and demonstrated better communicative self-efficacy than the female students did. They used the Perceptions of the Internet Survey (PIS) for surveying students' perceptions of the Internet, and found that students were more likely to perceive the Internet as technology and a tool. In the present study, hypotheses were that self-efficacy, general privacy concerns and amount of Facebook use would be significant factors for specific concerns about Facebook social media privacy. The rationale for these hypotheses is that both self-efficacy and the sense of having a private life are strong and ubiquitous constructs of personal identity, and that the strengths of these constructs would be reflected in one's concerns about control and privacy specifically related to use of Facebook.

\section{METHOD}

\section{Participants}

Participants were 284 out of 335 Texas State University undergraduate students who completed the survey. Participants who failed to complete the survey were excluded from the data set. Participants volunteered to participate in this study for class point incentives. There were 216 female students $(76.1 \%)$ and 68 male students $(23.9 \%)$. The mean age of the participants was $25(S D=1.799)$. A majority of participants (57\%) were White, Non-Hispanic, with $28 \%$ indicating Hispanic or Latino, 8\% Black or African-American, 4\% Asian or Asian American, $2 \%$ American Indian or Alaskan Native, and 1\% Hawaiian or other Pacific Islander. This study was granted an exemption by Texas State University's Institutional Review Board. 


\section{Survey Instrument And Procedure}

The survey instrument included demographic items, three items measuring Facebook use, three items measuring Facebook self-efficacy, six items measuring participants' feeling that they had Facebook personal privacy violations and three items measuring general Internet social media privacy concerns. Participants used a 10-point Likert scale estimating confidence level, ranging from not confident at all to very confident for each item.

Facebook use was defined as the summed responses to three items: estimated daily frequency (log-in rate), duration (average hr. per day), and number of friends. Facebook self-efficacy was defined by summing confidence estimates of three items: how to reset profile privacy levels, knowing the currently set level of profile privacy, and knowing who may be able to post on the profile. Facebook personal privacy violation was defined by summing six items concerning that others accessing their Facebook site, violating their privacy through tags and posts, and that Facebook itself was able to monitor and share personal information without their knowledge, violating Facebook personal privacy. The dependent measure, General Internet social media privacy concern, was measured by summing participants'1-10 scores for three items about concerns of SNS: posing a potential threat to general personal privacy, general gathering nonconsensual information, and general risk of personal profiles being violated.

Participants were instructed to honestly answer the survey items. Participants were recruited from upper-division psychology classes and offered course extra credit as incentive to complete the survey. The survey was presented in paper form with a corresponding answer key. To preclude any potential confound from comparing between-groups differences regarding Facebook use, privacy and self-efficacy, a within-subjects design was used and corresponding repeatedmeasures ANOVA was used for data analysis.

\section{RESULTS}

Separate alpha values were calculated for the three items measuring Facebook use (.71), three items measuring Facebook self-efficacy (.70), six items measuring participants' feeling that they had Facebook personal privacy violations (.75) and three items measuring general Internet social media privacy (.79). Cronbach's alpha measuring inter-item reliability for the 15 total Facebook and general Internet social media items was .74.

A univariate ANOVA was performed to determine the extent that Facebook self-efficacy, Facebook personal privacy violation and Facebook use were determinants of attitudes about general Internet social media privacy. Facebook selfefficacy was significant, $\mathrm{F}(2,281)=8.21, \mathrm{p} \geq .001$. Facebook personal privacy violation was also a significant, $F(2,281)=7.37, \mathrm{p} \geq .001$. However, Facebook use was shown to not be a significant factor for attitudes about general Internet social media privacy, $\mathrm{F}(2.281)=1.75, \mathrm{p} \leq .05$. 


\section{DISCUSSION}

This study examined Facebook use, self-efficacy (Bandura, 1997: Peng, Tsai, and $\mathrm{Wu}, 2006$ ) and privacy violations (Debatin et al., 2009; Brandtzæg, Lüders, and Skjetn, 2010) as determinants of attitudes about general Internet social media privacy concerns. As hypothesized, users who had high levels of Facebook selfefficacy felt strongly about general Internet personal privacy. This mirrors previous computer self-efficacy research, and also applies to Facebook (Compeau and Higgins, 1995) who reported self-efficacy was found to play an important role in shaping individuals' feelings and behaviors, and this also seems to be the case when using Facebook. This finding may seem paradoxical. However, having a heightened sense of self-efficacy may produce greater vigilance to perceived threats and a belief that while there are general threats to personal privacy, these participants feel they have the skill set needed to successfully defend against the general threats posed by SNS use. Concern about potential specific Facebook breeches of privacy by those accessing their site and by Facebook itself was a determinant of general Internet social media privacy risk perception. However, Facebook use, as measured by self-reported estimates of daily frequency, duration and numbers of friends was not a significant factor of participants' general Internet social media privacy concerns.

In 2011, the Federal Trade Commission (FTC) investigated Facebook over alleged privacy violations making aspects of users' profiles, such as name, picture, gender and friends list, public by default. The FTC alleged that Facebook engaged in deceptive behavior when it promised user privacy protections that it didn't fulfill. According to the Wall Street Journal, Facebook has agreed to a 20year privacy settlement with the FTC that would require the company to ask users for permission before changing the way their personal information is released. As a part of the settlement, Facebook has agreed to independent privacy audits every two years for a total of 20 years. If any violations are discovered, Facebook will have to pay $\$ 16,000$ in fines per violation. The privacy settings will stay the same as before, but any changes will now be "opt-in" instead of the "opt-out" preference Facebook was currently using. The settlement also requires that Facebook prevent access to a user's personal information if it has been more than 30 days since they deleted their profile. It seems that Facebook has finally learned to listen to their users, even if it took a government intervention to help achieve the result. Users are worried about their privacy on social networks, and it seems like these websites are heading in the right direction with regards to personal privacy.

One limitation of this study comes from the sample, which was a convenience sample of undergraduate students, composed mostly of psychology majors. Another limitation is the gender bias within the sample, with the majority of respondents being females. Further studies might address age and gender as factors predicting attitudes towards Facebook privacy. Also, research of privacy across several different social networking sites could be addressed. Generally, for users to feel more secure, the results of this study demonstrate the need for increased 
privacy on Facebook as well as the whole spectrum of social networks across the Internet.

\section{REFERENCES}

Bandura, A. (1994). Self-efficacy. In V. S. Ramachaudran (Ed.), Encyclopedia of human behavior (Vol. 4, pp. 71-81). New York: Academic Press. Reprinted in H. Friedman [Ed.], Encyclopedia of mental health. San Diego: Academic Press, 1998.

Bandura, A. (1997). Self-efficacy: The exercise of control. New York, NY, US: W H Freeman/Times Books/ Henry Holt \& Co.

Bandura, A. (2012). On the functional properties of Perceived self-efficacy revisited. Journal Of Management, 38(1), 9-44. doi:10.1177/0149206311410606

Barker, V. (2009). Older Adolescents' Motivations for Social Network Site Use: The Influence of Gender, Group Identity, and Collective Self- Esteem. CyberPsychology \& Behavior, 12(2), 209-213. doi:10.1089/cpb.2008.0228

Bargh, J.A., \& McKenna, K.A. (2004). The Internet and social life. Annual Review of Psychology, 55573-590. doi:10.1146/annurev.psych.55.090902.141922

Brandtzæg, P., Luders, M., \& Skjetne, J. (2010). Too Many Facebook 'Friends'? Content Sharing and Sociability Versus the Need for Privacy in Social Network Sites. International Journal of Human-Computer Interaction, 26(11/12), 1006-1030. doi:10.1080/10447318.2010.516719

Boyd, D. M., \& Ellison, N. B. (2007). Social network sites: Definition, history, and scholarship. Journal of Computer-Mediated Communication, 13(1), 210 230. doi:10.1111/j.1083-6101.2007.00393.x

Compeau, D.R., \& Higgins, C.A. (1995). Computer Self-Efficacy: Development of a Measure and Initial Test. MIS Quarterly, 19(2), 189-211.

Debatin, B., Lovejoy, J. P., Horn, A., \& Hughes, B. N. (2009). Facebook and online privacy: Attitudes, behaviors, and unintended consequences. Journal Of Computer-Mediated Communication, 15(1), 83-108. doi:10.1111/j.10836101.2009.01494.x

Duggan M. and Smith, A. (2014). Pew Research Center, January 2014, "Social Media Update 2013”. Retrieved February 18, 2014, from http://pewInternet. org/Reports/2013/Social-Media-Update.aspx

Facebook. (2008). Statistics. Retrieved March 21, 2011, from http://www.facebook.com/press/info.php?statistics

Facebook Settles FTC Charges That It Deceived Consumers By Failing To Keep Privacy Promises. (2011, November 29). Federal Trade Commission. Retrieved December 5, 2011, from http:/www.ftc.gov/opa/2011/11/privacysettlement.shtm

Gross, R. and Acquisti, A. (2005). 'Information Revelation and Privacy in Online Social Networks, WPES '05-Virginia USA, pp. 71- 8

Hargittai, E. (2007). Whose space? Differences among users and non-users of social network sites. Journal of Computer-Mediated Communication, 13(1), 
276-297. doi:10.1111/j.1083-6101.2007.00396.x

Hargittai, E., \& Hsieh, Y. (2010). Predictors and consequences of differentiated practices on social network sites. Information, Communication \& Society, 13(4), 515-536. doi:10.1080/13691181003639866

Joinson, A. N., Reips, U., Buchanan, T., \& Schofield, C. (2010). Privacy, Trust, and Self- Disclosure Online. Human-Computer Interaction, 25(1), 1-24. doi:10.1080/07370020903586662

Lin, N. (2001). Social capital: A theory of social structure and action. New York: Cambridge University Press.

Marsden, P. V. (1987). Core discussion networks of Americans. American Sociological Review, 52, 122-1

Peng, H., Tsai, C., \& Wu, Y. (2006). University students' self-efficacy and their attitudes toward the Internet: the role of students' perceptions of the Internet. Educational Studies, 32(1), 73-86. doi:10.1080/03055690500416025

Putnam, R. D., \& Goss, K. A. (2002). Introduction. In R. D. Putnam (Ed.), Democracies in flux: The evolution of social capital in contemporary society (pp. 3 - 19). New York: Oxford University Press.

Raice, S., \& Angwin, J. (2011, November 20). Facebook 'unfair' on privacy. Retrieved from http://online.wsj.com/article/SB10001424052970203441704 577068400622644374.html

Solove, D. J. (2008). THE END OF PRIVACY?. Scientific American, 299(3), 100-106. Retrieved from EBSCOhost.

Timm, D. M., \& Duven, C. J. (2008). Privacy and social networking sites. New Directions for Student Services, (124), 89-101. doi:10.1002/ss.297

Valenzuela, S., Park, N., \& Kee, K. F. (2009). Is there social capital in a social network site?: Facebook use and college students' life satisfaction, trust, and participation. Journal of Computer-Mediated Communication, 14(4), 875901. doi:10.1111/j.1083-6101.2009.01474.x

Youn, S. (2008). Parental influence and teens' attitude toward online privacy protection. Journal of Consumer Affairs, 42(3), 362-388. doi:10.1111/j.17456606.2008.00113.x

Youn, S. (2009). Determinants of online privacy concern and its influence on privacy protection behaviors among young adolescents. Journal of Consumer Affairs, 43(3), 389-418. doi:10.1111/j.1745-6606.2009.01146.x

Youn, S., \& Hall, K. (2008). Gender and online privacy among teens: Risk perception, privacy concerns, and protection behaviors. Cyber Psychology \& Behavior, 11(6),763-765. doi:10.1089/cpb.2007.0240

Zhao, S. (2006). Do Internet Users Have More Social Ties? A Call for Differentiated Analyses of Internet Use. Journal of Computer-Mediated Communication, 11(3), 844-862. doi:10.1111/j.1083-6101.2006.00038.x 
